\title{
Food loss and waste metrics: a proposed Nutritional Cost Footprint from linear programming and life cycle assessment
}

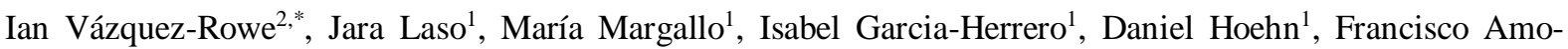
Setién ${ }^{1}$, Alba Bala ${ }^{3}$, Rebeca Abajas ${ }^{1}$, Carmen Sarabia ${ }^{1}$, María Jesús Durá1 ${ }^{1}$ Pere Fullana-i-Palmer ${ }^{3}$, Rubén Aldaco ${ }^{1}$

${ }^{1}$ University of Cantabria, Avda. de los Castros s/n, 39005, Santander, Spain

${ }^{2}$ Peruvian LCA Network, Department of Engineering, Pontificia Universidad Católica del Perú, Av. Universitaria 1801, San Miguel, Lima 15088, Peru

${ }^{3}$ UNESCO Chair in Life Cycle and Climate Change, Escola Superior de Comerç International (ESCI-UPF), Pg. Pujades 1, 08003 Barcelona, Spain

*Corresponding author: Ian Vázquez-Rowe. E-mail: ian.vazquez@pucp.pe

\section{Abstract}

Purpose The main purpose of this article is to assess the nutritional and economic efficiency of food loss and waste (FLW) along the supply of 13 food categories included in the Spanish food basket by means of the definition of a new method which combines two indexes.

Methods The Nutrient Rich Foods index and the economic food loss and waste (EFLW) index were combined by means of linear programming to obtain the Nutritional Cost Footprint (NCF) indicator under a life cycle perspective. The functional unit used was the daily supply of food for a Spanish citizen in year 2015.

Results and discussion Results showed that vegetables and cereals were the food categories most affected by the inefficiencies in the food supply chain under a nutritional perspective, being agricultural production and household consumption the main stages in which the nutritional content of food is lost or wasted. Moreover, according to the NCF index, vegetables represented $27 \%$ of total nutritional-economic wastage throughout the entire Spanish agri-food chain. They are followed by fruits, which add up to $19 \%$. Hence, specific food waste management strategies should be established for these specific products and supply stages. Finally, the sensitivity analysis performed highlighted that results were mostly independent from the importance attributed to either nutritional or economic variables.

Conclusions The methodology described in this study proposes an indicator quantifying the nutritional-economic cost of different food categories in the Spanish food basket. This NCF indicator makes it possible to define reduction strategies to promote the use of food waste fractions for waste-to-energy valorization approaches or the extraction of different types of pharmacological, chemical or cosmetic compounds.

Keywords: food waste; life cycle assessment; linear programming; nutritional cost footprint 


\section{Introduction}

According to the Food and Agriculture Organization of the United Nations (FAO), approximately one third of all food is lost or wasted worldwide throughout the supply chain (Gustavsson et al. 2011). After several years of awareness, food loss and waste (FLW) has gradually become a mainstream environmental concern. In fact, the United Nations has included FLW in its Sustainable Development Goals (SDGs). More specifically, SDG 12.3 aims at halving per capita global food waste at the retail and consumer levels, as well as reducing food loss along production and supply chains by 2030 (UN 2019). Therefore, it is evident that reducing FLW is one of the several necessary measures to meet the increasing challenge of feeding the world's population sustainably, reducing the energy consumption and greenhouse gases emissions (GHG) attributed to agri-food systems (Pimentel et al. 2008), as well as other related environmental impacts (e.g., water footprint or eutrophication). For instance, Grizzetti and colleagues (2013) determined that 2.7 Tg of nitrogen are lost on an annual basis due to food waste at consumption. In terms of GHG emissions, Heller and Keoleian (2015) suggested that food loss adds a daily $1.4 \mathrm{~kg} \mathrm{CO}$ eq per capita to the average US diet. In similar terms, Vázquez-Rowe and colleagues (2017a) estimated that approximately $210 \mathrm{~kg} \mathrm{CO}$ eq per capita and year is generated by FLW up to the point of purchase by citizens, considering the average Peruvian diet. A recent study Laso et al. (2018a) estimated up to 70\% energy savings for the Spanish agri-food sector if appropriate waste management actions are taken.

The European Waste Framework Directive determines the hierarchical actions to manage waste, including food waste, based on prevention and environmental criteria (Cristobal et al. 2008). Member States must apply the waste hierarchy perspective, a priority order at the top of which is waste prevention, followed by preparing for re-use, (redistribution) recycling, (energy) recovery and disposal. In the context of FLW, the hierarchy is supported by obligations to: divert proportions of biodegradable municipal waste from landfill; take 'appropriate measures to encourage' the separate collection of biowaste with a view to composting and digestion; and, take necessary measures ‘designed to achieve’ an increase in levels of household waste recycling to 50\% by 2020 .

Currently, a recovery/reuse-recycling imbalance exists owing to a preference for profitable waste management (recovery for example as anaerobic digestion) over charitable waste prevention (food redistribution), which favors commercial interests over the interests of those suffering from malnourishment or hunger. In this context, food waste management requires to take all 'reasonable' measures to apply the waste hierarchy approach, taking into account technical feasibility and economic viability, as well as ethical concerns. An issue that has been repeatedly minimized or directly omitted in the governance of FLW is the fact that it actually consists of a reservoir 
complex carbohydrates, lipids or proteins to be used as raw material for fuel production and other industrially viable compounds (Ravindran and Jaiswal 2016). Moreover, depending on the characterization of food waste, this type of waste can present a very high variability in terms of valuable nutrients (Eriksson et al. 2015; Nemecek et al. 2016). For instance, the properties of food waste will not be the same in nations with low meat consumption (e.g., India) as compared to nations with a higher reliance on red meat (e.g., Luxembourg or the United States). This variability can be extrapolated to different types of diets in the case of food waste, whereas in the case of food loss in supply chains it is common for the waste to be relatively homogeneous.

Consequently, the main hypothesis of this work is to consider that the 'importance' and 'difference' of food has direct implications in the management of its waste. Food has a profound importance to humanity as a resource, given its intrinsic usage value as one of the few basic human needs, as well as a commodity, so that it also has a trading value. Food also serves social and cultural roles, so that food is often consumed for purposes beyond sustenance, and can be akin to a material good. On the other hand, notwithstanding the potential climate benefits of energy from food waste, redistributing food to humans (and animals) is generally more resource efficient than sending it to recovery. Finally, not all food is of equal calorific and nutritional value, so nutritional content of food waste should be considered in the decision making process (Bradshaw 2018).

In order to contribute to simplify the decision making process, it is necessary that future strategies to reduce FLW consider not only their quantification in terms of mass, but also the nutritional qualities attributed to food and the economic value of food lost, at all stages of the supply chain. Therefore, the main objective of the study is to estimate FLW along the supply chain of the Spanish food system in terms of nutritional and economic cost using a life cycle perspective. For this, an indicator that jointly uses linear programming and optimization tools was applied to combine nutritional and economic variables. The results of this study are intended to be of utility for policy-makers, since the metrics proposed will allow them to include qualitative aspects in their decision-making process when analyzing FLW. Similarly, the indicator that is created can be used by academia to evaluate diets and FLW in other temporal or geographical contexts other than the case study proposed in the current research.

\section{Materials and Methods}

The methodology described in this study is based on a life cycle perspective since it considers all the stages of the supply chain of food products. This methodology is divided into the four steps defined by the Life Cycle Assessment (LCA) methodology (ISO 2006a, b). Firstly, the goal and scope definition step consists of a detailed definition of the intended objective of the study defining the functional unit (FU) and the system boundaries 
(Hellweg and Milà i Canals 2014). Thereafter, it is necessary to elaborate an extensive life cycle inventory (LCI) in which the main inputs and outputs of the products life cycle are collected (Yang 2016). In this case, it was necessary a deep analysis of the inputs and output of different food products along their supply chain by means of a Material Flow Analysis (MFA), as well as an exhaustive nutritional analysis. Once the data were collected, the Life cycle Impact Assessment (LCIA) was carried out. In this study, the combination of two indicators, nutritional and economic, was used to define the Nutritional Cost Footprint (NCF) of different food categories.

\subsection{Goal and Scope definition}

The goal and scope of this study was to assess the nutritional and economical cost of FLW along the supply chain of the Spanish food basket by means of the definition of a new method that combines two indexes. On the one hand, the selected nutritional indicator was the Nutrient Rich Foods (NRF9.3) score (Fulgoni et al. 2009; Streppel et al. 2014). On the other hand, the economic FLW (EFLW) indicator was created to account for the economic value of FLW generated for each food product. Both indicators and their combination to establish the NCF score are further discussed in Section 2.4. The results are expected to test the viability of the new NCF index defined and to provide an overview regarding the nutritional cost of the different food categories under study with the aim to identify the most inefficient under a nutritional and economical point of view.

\subsection{Functionality and System Boundaries}

The function of the system is the provision of food, with a balanced set of nutrients to an average Spanish citizen, with high efficiency rates and minimizing FLW. Therefore, the identification of those food categories, which present high nutritional and economic efficiency, is critical in this study. To quantify this function, it is necessary to define a FU, to which all the inputs and outputs will be referred. In this case, the FU was defined as the daily supply of food for a Spanish citizen in the year 2015 in terms of food categories, which is equivalent to 2,510 kcal per day. The system boundaries in this study comprise the entire supply chain of a food system, following recent studies by García-Herrero et al. (2018) and Batlle-Bayer et al. (2019). Therefore, the stages of food production, processing and packaging, distribution and consumption were taken into account, as shown in Figure 1, as well as FLW throughout the entire food supply chain.

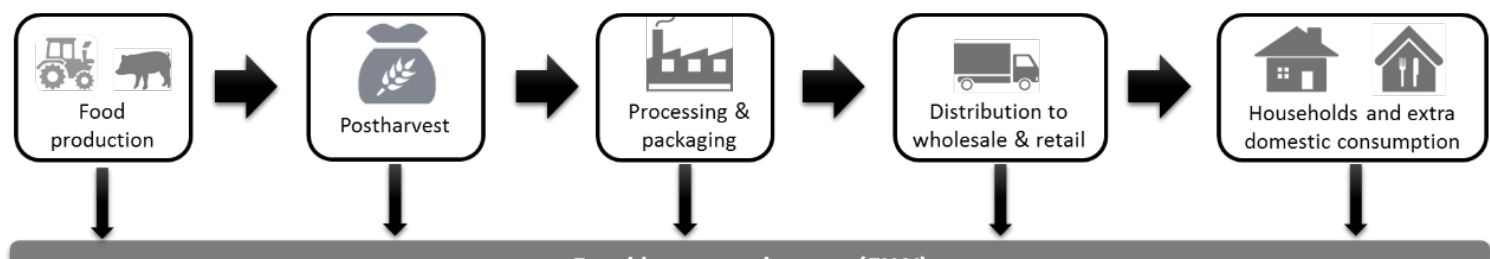

Food losses and waste (FLW)

Figure 1. Overview of the system boundaries in this study. 


\section{3. $\quad$ Life Cycle Inventory (LCI)}

Following the nutritional recommendations set by the Spanish Agency of Food Security and Nutrition (AECOSAN) and the Spanish Society of Community Nutrition (SENC), a basket of food products was selected based on the consumption data reported by the Spanish Ministry of Agriculture, Fisheries and Food (MAPAMA) (MAPAMA, 2017). A total of 53 representative food commodities were sourced and classified in 13 categories: fruits, vegetables, cereals, dairy, vegetable fats, nuts and seeds, fish, white meat, eggs, red meat, legumes and derivatives, potatoes and sweets. These categories were selected based on the eleven categories used FAOSTAT classification. However, in the current study meat was divided into white and red meat, and a specific category for nuts and seeds was added. The rationale behind these modifications is linked to the differentiated nutritional properties between red and white meat, as well as the specific health benefits of nuts and seeds (Lovejoy 2005; de Souza et al. 2017). Data regarding the life cycle of the different representative food commodities studied were collected from the MFA developed by García-Herrero et al. (2018), in which the production values were mainly sourced from Eurostat (Eurostat 2015a, 2015b, 2015c, 2015d). Imported food products were taken into account based on trade statistics compiled by the Spanish Tax Agency (AEAT) (Datacomex, 2018). To estimate FLW, different percentage losses were considered for each life cycle stage (i.e., agricultural production, postharvest, industrial processing, distribution and consumption) from different sources. For instance, MAPAMA (2013) and Gustavsson et al. (2013) were used to determine losses in agricultural production and industrial losses. In contrast, postharvest losses were estimated using FAOSTAT datasheets (FAO, 2015). Finally, food waste rates at the distribution and consumption stages were obtained from the FAO Food Balance Sheets for Spain in 2013 (FAO, 2015). For further details on these assumptions, please refer to Garcia-Herrero et al. (2018). Table S2 of the Supporting Material presents the FLW of the 53 representative food commodities studied in each life cycle stage. Since this study relies heavily on the loss percentages reported by FAO, our FLW definition is based on the definition provided by FAO: food loss and waste refers to any substance, whether processed, semi-processed or raw, which was initially intended for human consumption but was discarded or lost at any stage of the supply chain. It concerns to every non-food use, including discarded food that was originally produced for human consumption and then recycled into animal feed (FAO, 2015).

Nutritional data were obtained from the food composition tables of the Spanish Institute for Education in Nutrition and Dietetics (Farran et al. 2004). Table S1 of the Supporting Material collects the nutritional composition of each food commodity studied in terms of the nutrients needed to estimate the NRF9.3 index. 
Regarding economic data, they were obtained from the Spanish Ministry of Economy and Competitiveness (MINECO, 2015) and the Spanish Ministry of Agriculture, Fishery, Food and Environment (MAPAMA, 2015). Prices were considered at origin, wholesale and consumer level. Same cost were assumed for FL at agricultural production and postharvest stages. Regarding the processing stage, economic value of production reported by Eurostat were used when consistent data were available. Otherwise, wholesale process were used for processing and distribution stages. It was assumed that food service establishment a related extradomestic services can buy their food at lower prices than private households, considering a 5\% volume discount. The cost of disposal was not included because this stage was out of the system boundaries. Table S2 in the Section 4 of the Supporting Material collects the prices at origin, wholesale and consumer level for the food categories under study.

\subsection{Nutritional Cost Footprint (NCF) estimation}

The Healthy Eating Index (HEI) is a measure of diet quality used to assess how well a set of food commodities align with key recommendations of the Dietary Guidelines for Americans (Kennedy et al. 1995). In 2005, the Dietary Guidelines for Americans identified additional nutrients of concern that were underrepresented in the typical U.S. diet (Guenther et al. 2008). For instance, fiber, vitamins A, C and E, calcium, potassium and magnesium for adults and fiber, vitamin E, calcium potassium and magnesium for children and adolescents (Fulgoni et al. 2009). However, other authors, such as Drewnowski et al. (2008, 2009), selected a number of nutrient-rich foods (NRF) index for testing and validation against HEI scores. This index, named NRFn.3, was based on $n$ nutrient to encourage and on 3 to be limited. As Table 1 shows, the number of nutrient to encourage was variable ( $n=6-15)$ whereas the 3 to be limited were always constant: saturated fat, added sugar and sodium.

In this study, the NRF9.3 index was used in order to determine the nutritional impact of FLW. The NRF9.3 index is based on 9 nutrients to encourage, including protein, fiber, minerals calcium, iron, magnesium and potassium and vitamins A, C and E and the 3 nutrients to be limited (LIM) per reference amounts customarily consumed (RACC) and per 100 kcal (Equation 1). According to Fulgoni et al., 2009, the NRF9.3 per 100 kcal and per RACC presents the best ability to predict HEI and can be readily expected to rank foods based on nutrient density. This index is the most commonly used in literature, so it is possible to compare the results to other studies. For example, Drewnowski (2010) uses the NRF9.3 index to identify healthy, affordable foods and food groups. Sluik et al. (2015) evaluated fifteen NRF index scores, the NRF9.3 between them, against the Dustch Healthy Diet Index (DHD-index). On the other hand, Fulgoni et al. (2009) ranked foods based on their nutrient composition 
using the NRF9.3 index. Therefore, authors decided to use the NRF93 index in order to facilitate its comparison with other studies.

$$
N R F 9.3=\sum_{i} w_{i}\left(\sum_{l=9} \frac{N R_{l}}{D V_{l}} \cdot 100-\sum_{m=3} \frac{L I M_{m}}{M R V_{m}} \cdot 100\right)
$$

where $N R$ is the intake of nutrient $l$ to encourage, $D V$ is the daily recommended value of nutrient $l, L I M$ is the intake of nutrient $m$ to be limited and $M R V$ is the maximum daily recommended value for nutrient $m$. In addition, $w_{i}$ is the weighting factor of food category $i$, and can be estimated on kcal or weight basis. In this work, the weight basis has been selected to avoid the overrepresentation of calorie-dense foods, considering the daily supply of food for a Spanish citizen in the year 2015 in terms of food category according to the defined FU. Table 2 collects the yearly DV values based on daily recommended values from EFSA (2017) and yearly MRV values based on the healthy diet defined by the WHO (2015).

Table 1. Nutrients to encourage and LIM in selected NRF nutrient profile models (Fulgoni et al. 2009).

\begin{tabular}{|c|c|c|c|c|}
\hline NRF models & Macronutrients & Vitamins & Minerals & LIM \\
\hline LIM & & & & Saturated fat, added sugar, $\mathrm{Na}$ \\
\hline LIMt & & & & Saturated fat, added sugar, $\mathrm{Na}$ \\
\hline NRF6.3 & Protein, fiber & A, C & $\mathrm{Ca}, \mathrm{Fe}$ & Saturated fat, added sugar, $\mathrm{Na}$ \\
\hline NRF9.3 & Protein, fiber & A,C, E & $\begin{array}{l}\mathrm{Ca}, \mathrm{Fe}, \\
\mathrm{Mg}, \mathrm{K}\end{array}$ & Saturated fat, added sugar, $\mathrm{Na}$ \\
\hline NRF11.3 & Protein, fiber & A, C, E, B-12 & $\begin{array}{l}\mathrm{Ca}, \mathrm{Fe}, \\
\mathrm{Mg}, \mathrm{Zn}, \mathrm{K}\end{array}$ & Saturated fat, added sugar, $\mathrm{Na}$ \\
\hline NRF15.3 & $\begin{array}{l}\text { Protein, fiber, } \\
\text { monounsaturated fat }\end{array}$ & $\begin{array}{l}\text { A, C, D, E, thiamin, } \\
\text { riboflavin, B-12, folate }\end{array}$ & $\begin{array}{l}\text { Ca, Fe. Zn, } \\
\text { K }\end{array}$ & Saturated fat, added sugar, Na \\
\hline
\end{tabular}

Table 2. Daily recommended values (DVs) and maximum values (MRVs) per capita (Batlle-Bayer et al. 2019).

\begin{tabular}{llll}
\hline Nutrients & Unit & DVs (EFSA, 2017) & MRVs (WHO, 2015) \\
\hline Protein & g & 52.9 & - \\
Fiber & g & 24.9 & - \\
K & $\mathrm{mg}$ & 3560 & - \\
$\mathrm{Ca}$ & $\mathrm{mg}$ & 822 & - \\
Fe & $\mathrm{mg}$ & 14.0 & - \\
$\mathrm{Mg}$ & $\mathrm{mg}$ & 375 & - \\
Vitamin A & $\mathrm{mgg} \mathrm{ER}$ & 800 & - \\
Vitamin C & $\mathrm{mg}$ & 80.0 & - \\
Vitamin E & $\mathrm{mg}$ ET & 12.0 & - \\
Saturated fat & $\mathrm{g}$ & - & 20.1 \\
Added sugar & $\mathrm{g}$ & - & 90.3 \\
Na & $\mathrm{mg}$ & - & 2400 \\
\hline
\end{tabular}

In terms of the economic quantification of FLW, this was determined according to Equation 2:

$$
E F L W_{i}=\sum_{j} F L W_{i, j} \cdot V_{i, j}
$$


where $E F L W_{i}$ represents the economic food loss and waste of food category $i, F L W_{i, j}$ is the food loss and waste of food category $i$ in the supply stage $j$ and $V_{i, j}$ their corresponding economic value.

Based on the combination of the NRF9.3 and EFLW indexes, the food categories were classified intro three categories: A, B and C. A rating letter "A" is applied to food categories that exhibit the lowest nutritional and economic loss and waste, while rating "C" represents the exact opposite (i.e., highest nutritional and economic loss and waste). The reference value used to fix the segregation between these categories was the terciles obtained from the entire sample. This methodology, based on the combination of two indicators has been used by LorenzoToja et al. (2016) and Laso et al. (2018b), which combined environmental and economic impacts to define the eco-efficiency of a set of 22 wastewater treatment plants in Spain and of different anchovy-based processed products, respectively.

In some scenarios, decision-making is subjected to a certain level of uncertainty based on the weighting decision considered to balance the nutritional and economical aspects. Therefore, it is necessary to introduce a methodological approach that facilitates the decision-making process. The Nutritional Cost Footprint (NCF) index is proposed to jointly assess the nutritional and economic impact of FLW. In this context, linear programming is applied to estimate the weighting factors that lead to an optimized global value of NCF. The methodology is composed of a normalization step that relates the magnitude of impacts throughout different impact categories to reference values, and a weighting step, which aggregates the two indicators.

Normalization is required to render the variables comparable and facilitates the comparison among indicators. In the current study, internal normalization was applied to NRF9.3 and EFLW impacts dividing by the highest value of NRF9.3 and EFLW within the sample. Finally, the weighting procedure ranks the different indexes according to their relative importance following Equation 3:

$$
N C F_{i}=\alpha_{i} \frac{N R F 9.3_{i}}{\overline{N R F 9.3}}+\beta_{i} \frac{E F L W_{i}}{\overline{E F L W}}=\alpha_{i} \mathrm{~N}_{i}^{*}+\beta_{i} \mathrm{C}_{\mathrm{i}}^{*}
$$

Where $\overline{N R F 9.3}$ is the reference value of NRF9.3 and $\overline{E F L W}$ is the reference value of EFLW; $\alpha_{i}$ is the weighting factor for the normalised value of the nutritional impact $\left(\mathrm{N}_{i}^{*}\right)$ and $\beta_{i}$ is the weighting factor for the normalized economic impact $\left(\mathrm{C}_{\mathrm{i}}^{*}\right)$ of FLW. Equal weighting is usually applied in the literature as a first approximation for constructing a composite index. Hence, for comparison issues, the two indicators are first assumed to be equally relevant. Nevertheless, this approach can disguise the absence of statistical or empirical bases for determining the weights. Therefore, the current study applies the LP weighting approach defined by Garcia-Herrero et al. (2017) to calculate the optimized values of $\alpha_{i}$ and $\beta_{i}$ and estimating the NCF in terms of maximization. The optimization of Equation 3 in terms of maximization will allow determining the best nutritional 
and economical performing system in the worst scenario. That is to say, when a food category presents high NCF, this means that its FLW involves substantial economic and nutritional losses and, therefore, reduction strategies should be addressed.

s.t. $\quad \sum_{\mathrm{i}=1}^{\mathrm{i}} \alpha_{\mathrm{i}}+\sum_{\mathrm{i}=1}^{\mathrm{i}} \beta_{\mathrm{i}}=1$

The limits of the weighting factors were determined by correlating the different metrics. These relationships have been taken as a constraint for determining the lower and upper bounds of $\alpha_{\mathrm{i}}$ and $\beta_{\mathrm{i}}$.

$$
\begin{array}{ll}
\text { s.t. } & 0.01 \leq \alpha_{i} \leq w_{1, i} \alpha_{1} \\
& 0.01 \leq \beta_{i} \leq w_{2, i} \alpha_{1}
\end{array}
$$

where $\mathrm{w}_{1, \mathrm{i}}$ and $\mathrm{w}_{2, \mathrm{i}}$ are the factors to determine $\alpha_{\mathrm{i}}$ and $\beta_{\mathrm{i}}$, respectively. It has also been assumed that every environmental impact has a minimum weight $\left(\alpha_{i, \min }=\beta_{i, \min }=0.01\right)$ so that none of them are neglected.

\section{Results and Discussion}

\subsection{Nutritional analysis of the FLW}

Prior to the estimation of the value of the NRF9.3 index, it is necessary to determine the nutritional loss linked to FLW in each food category. Figure 2 displays the nutritional losses of the 9 nutrients to encourage and Figure 3 shows the 3 nutrient to limit for each food category and divided into the food life cycle stages (i.e., agricultural production, postharvest, processing, distribution and household consumption). The analysis of FLW reveals that vegetables and cereals were the food categories most affected by the inefficiencies in the food supply chain. Regarding the former, its highest nutritional loss was estimated at $645 \mathrm{mg} \mathrm{cap}^{-1}$ day $^{-1}$ of potassium, 860 mcg ER cap ${ }^{-1}$ day $^{-1}$ of vitamin A and $60 \mathrm{mg} \mathrm{cap}^{-1} \mathrm{day}^{-1}$ of vitamin C. Other significant values of nutritional loss due to vegetables FLW were fiber (4.2 $\left.\mathrm{g} \mathrm{cap}^{-1} \mathrm{day}^{-1}\right)$ and calcium (61 $\mathrm{mg} \mathrm{cap}^{-1}$ day $\left.^{-1}\right)$. Vegetables were followed by the cereals category, whose nutritional loss was notable for fiber ( $\left.4.9 \mathrm{~g} \mathrm{cap}^{-1} \mathrm{day}^{-1}\right)$, iron $\left(2.3 \mathrm{mg} \mathrm{cap}^{-1}\right.$ day $\left.^{-1}\right)$ and magnesium (51.4 $\mathrm{mg} \mathrm{cap}^{-1}$ day $^{-1}$ ). These results are correlated to those obtained by García-Herrero et al. (2018), in which vegetables are the food category with the highest FLW, around $192 \mathrm{~g} \mathrm{cap}^{-1}$ day $^{-1}$, followed by cereals, whose contribution to the total FLW is around $20 \%$. Regarding the 3 nutrients to limit, the results are variable, with cereals, fruits and vegetable oils as the food categories with the highest loss of saturated fats, added sugar and sodium, respectively.

In general, agricultural production and household consumption were the main stages in which the nutritional content of food is lost or wasted. As shown Figure 4, in the average of all food categories, around 50\% of nutrient loss is produced in the agricultural production stage for all the 9 nutrients to encourage, except for proteins where the greatest nutritional loss is produced at the household. Regarding the 3 nutrients to limit, also 
approximately $50 \%$ of nutritional loss was produced in the agricultural production stage. This trend in the results is in agreement with the results obtained by Garcia-Herrero et al. (2018) which states that household consumption is the main step contributing to food waste, around $241 \mathrm{~g} \mathrm{cap}^{-1}$ day $^{-1}$, followed by agricultural production and postharvest stages. These contributions are higher for fruits and vegetables owing to climatic conditions, diseases and pest. 

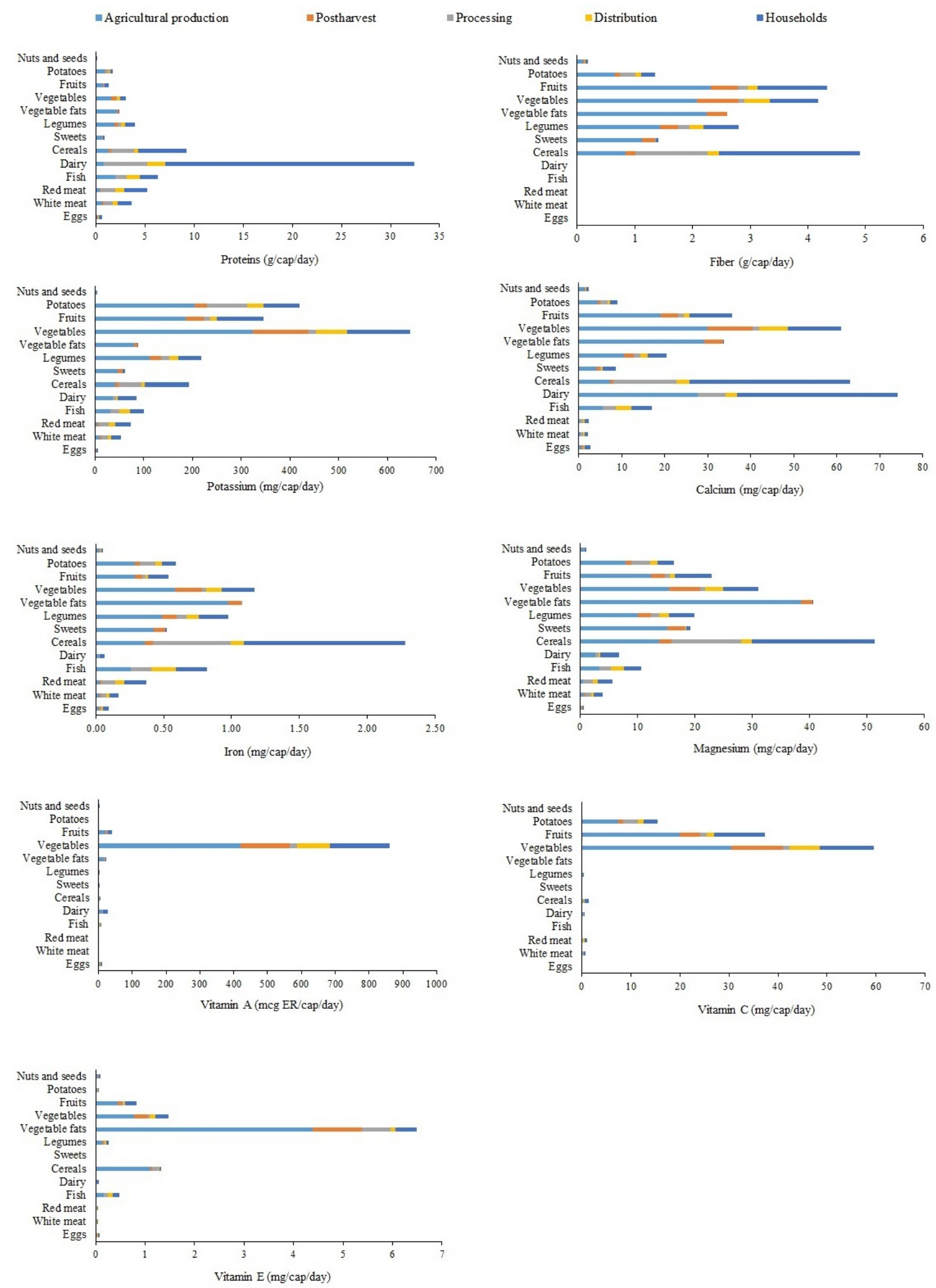

Figure 2. Nutritional food loss and waste (FLW) for the selected 9 nutrients to encourage of each food category and life cycle stage based on the functional unit (FU): the daily supply of food for a Spanish citizen in the year 2015 in terms of food categories. 

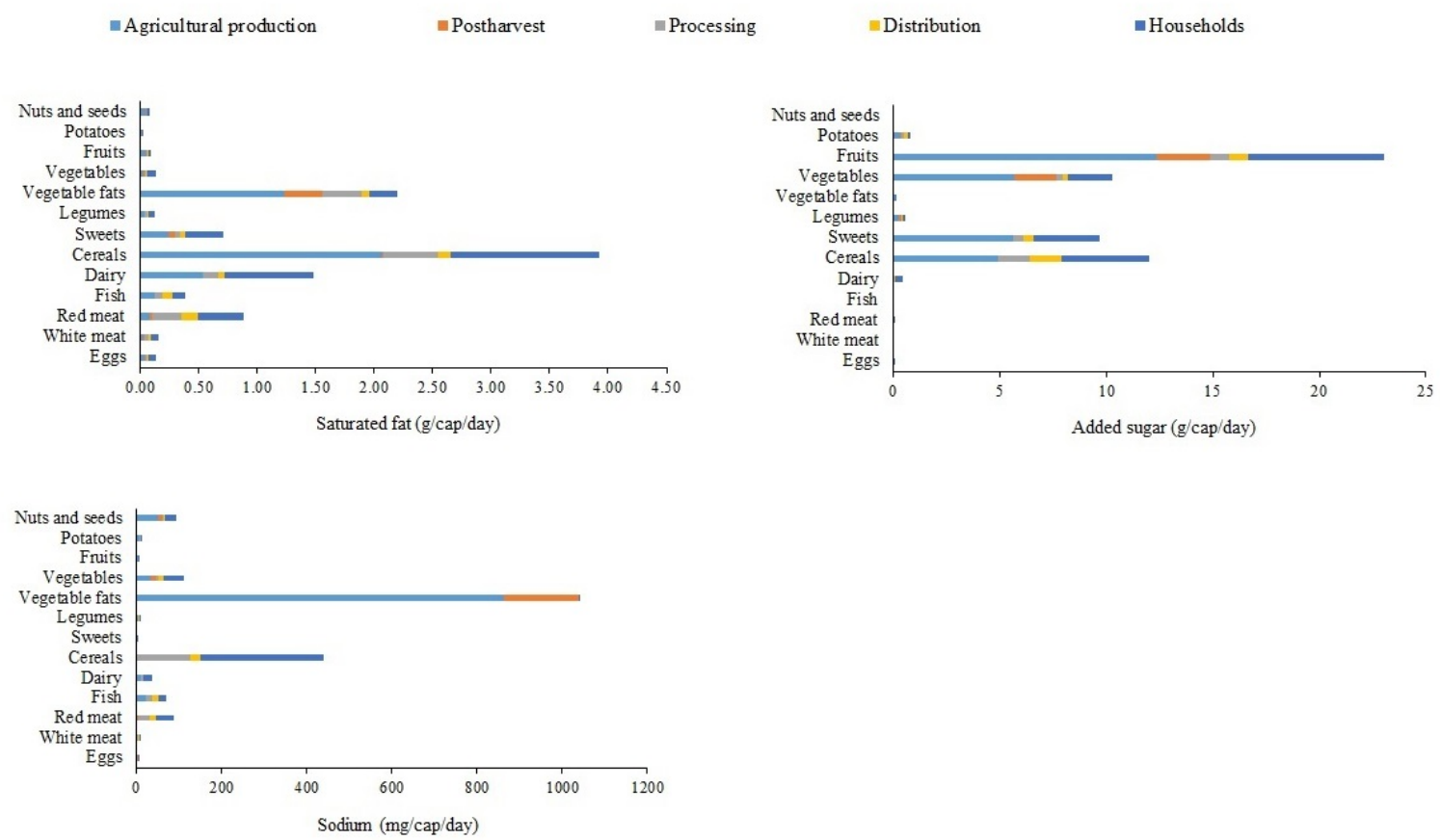

Figure 3. Nutritional food loss and waste (FLW) for the selected 3 nutrients to limit for each food category and life cycle stage based on the functional unit (FU): the daily supply of food for a Spanish citizen in the year 2015 in terms of food categories.

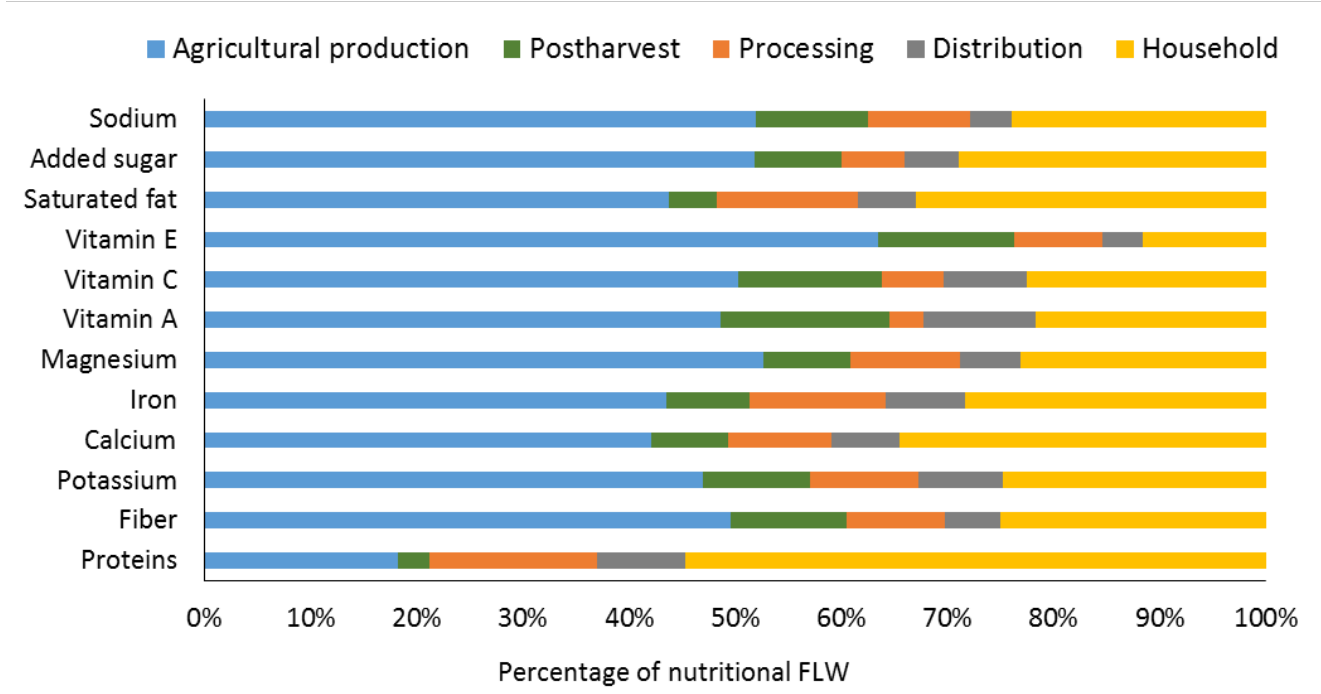

Figure 4. Relative contribution of each stage of the food life cycle to nutritional loss.

\subsection{Nutritional cost analysis of the FLW}

Based on nutritional analysis of the FLW, performance terciles have been defined to sort the different food categories according to the intensity of the nutritional-economic wastage. Figure 5 shows the NRF9.3 and EFLW for each food category. According to the computed results, vegetables, fruits, vegetable fats, red meat, 
dairy and cereals were the food categories that show the worst nutritional-economic efficiency, while the best results were shown by sweets and eggs. In particular, vegetables, vegetable fats, red meat and fruits presented the highest EFLW values. These categories, together with cereals and dairy products appear in tercile C, as shown in Figure 4. This is in agreement with the results obtained by García-Herrero et al. 2018, where the red meat and animal fat categories were found to be the largest contributor to economic wastage, followed by the fruits and vegetables categories. Interestingly, as opposed to red meat, white meat (e.g. chicken) and especially seafood present higher performance rates. In fact, seafood shows the third best performing food category, although it is noted rated with an A as the latter. Other categories, such as potatoes, legumes and nuts and seeds also appear in tercile B, all of which show very low NRF9.3 values and moderate EFLW. Therefore, based on these aggregated results, it can be concluded that those diets that include red meat and vegetables on the menu, such as the Atlantic or Mediterranean diets in Spain, involve low nutritional-economic efficiency due to the FLW generated.

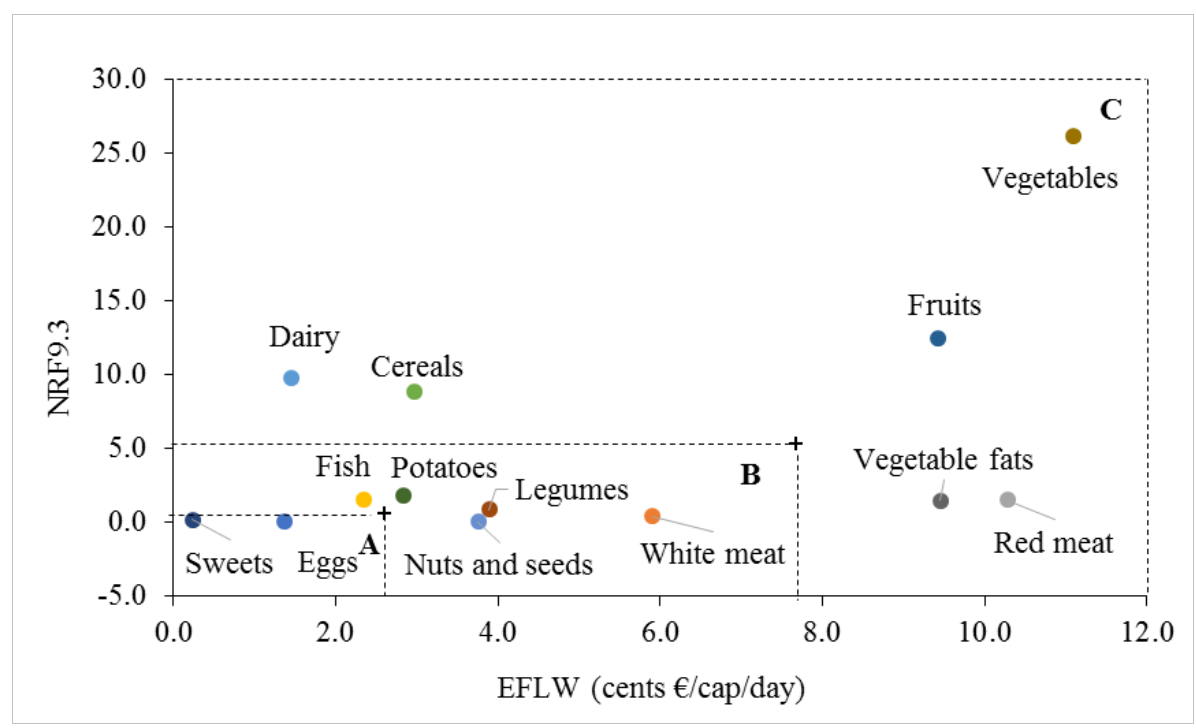

Figure 5. NFR9.3 of food loss and waste (FLW) versus EFLW (cents $€ /$ cap/day) for the categories under study. Results are referred to the functional unit (FU): the daily supply of food for a Spanish citizen in the year 2015 in terms of food categories.

For transparent interpretation, Figures 6 and 7 represent the NRF9.3 and EFLW index differentiated by stages of the supply chain for a better and easier understanding for the reader, which can compare the aggregated results with the individual results. Following the trend of previous results, these figures confirm the importance of both index in the agricultural production and household stages. 


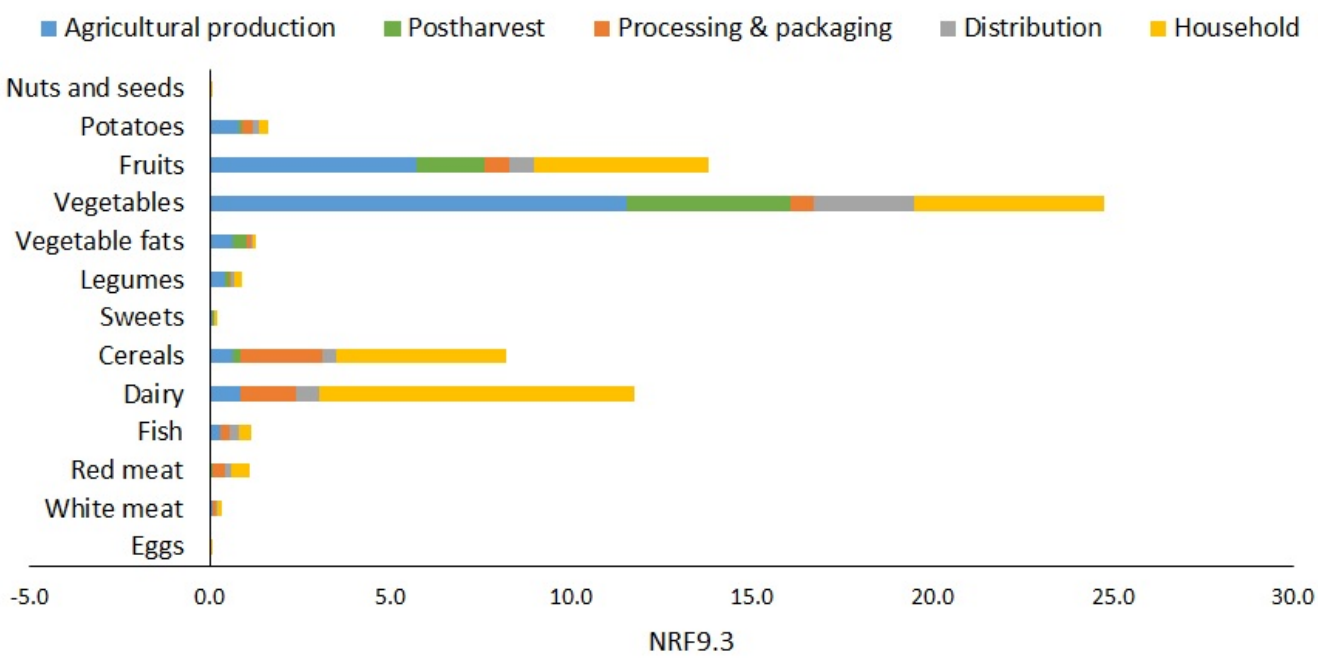

Figure 6. NFR9.3 of food loss and waste (FLW) for each food category and life cycle stage based on the functional unit (FU): the daily supply of food for a Spanish citizen in the year 2015 in terms of food categories.

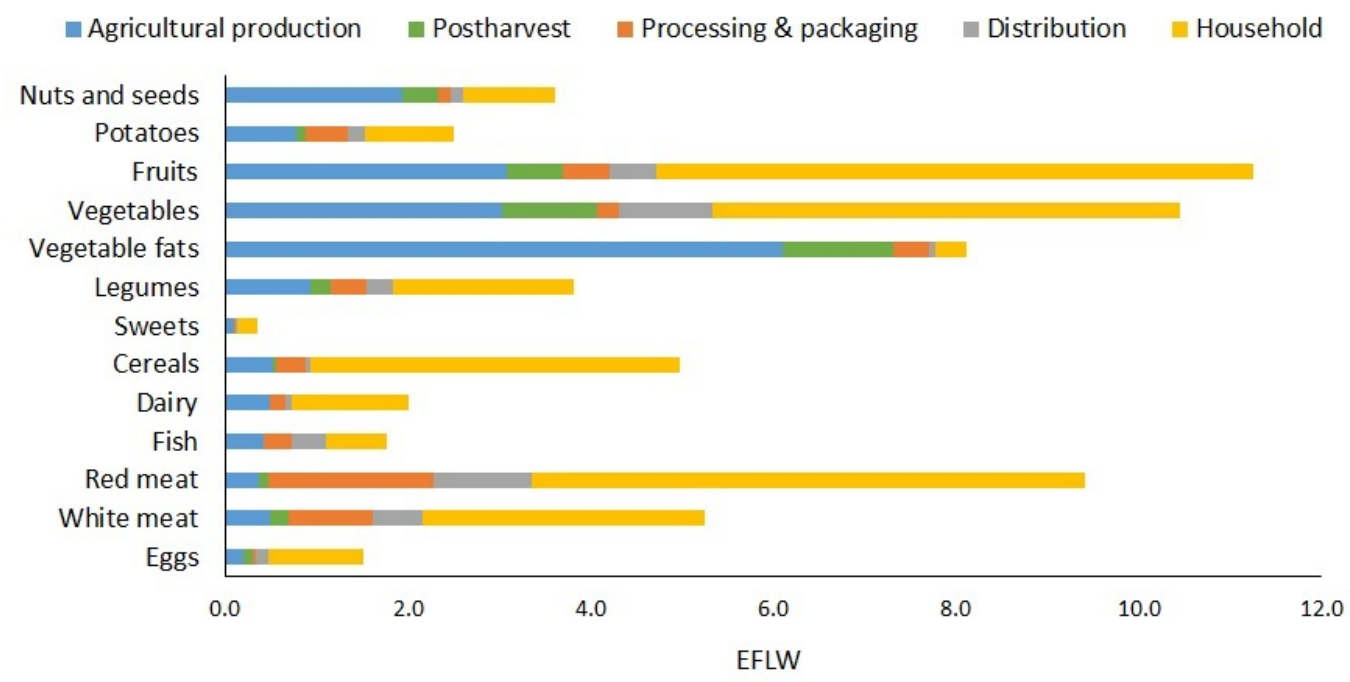

Figure 7. Economic food loss and waste (EFLW) for each food category and life cycle stage based on the functional unit (FU): the daily supply of food for a Spanish citizen in the year 2015 in terms of food categories.

Although the rating method can be illustrative to show which food commodities require larger efforts, it fails to provide a quantitative measure of the quality of FLW. In this sense, scores have been normalised and weighted to calculate the optimum NCF. Results show that vegetables presents the highest NCF value (14.7) representing $20 \%$ of nutritional-economic wastage throughout the Spanish agri-food chain. They are followed by fruits, with a NCF value of 12.4, which represent $17 \%$. Therefore, such categories are considered to be critical since their FLW involves high economic and nutritional losses. Therefore, reduction strategies in these categories should be prioritized. Interestingly, these (i.e. vegetables and fruits) also represent the most energy intensive fractions, being the most profitable for bioenergy production if FLW minimization strategies fail. Conversely, 
sweets (0.5\%) and eggs (2.1\%) appear as the most efficient supply chains with the lowest NCF values, 0.34 and 1.5 , respectively.

Figure 8a provides a graphical representation of the life cycle stage where the optimized values of NCF is occurring. As observed, results for the three categories with highest NCF (i.e. vegetables, fruits and vegetable fats), demonstrate that agricultural production is a critical stage in terms of high generation of nutritionaleconomic loss. Legumes, nuts and seeds and potatoes also show a high NCF generated in this stage, although the overall impact of these categories is much lower. In the case of seafood, most of the food loss in this stage corresponds to discards from marine fishery landings. For this category, it should be noted that the discards assumed are those reported by the FAO report developed by Gustavsson et al. (2011). On the one hand, a study by Vázquez-Rowe and colleagues (2011) elevated discarding for the Galician fishing fleet in NW Spain substantially as compared to the reference values provided by FAO. On the other, it is important to bear in mind that as of January 2016 the European Commission has enforced a stricter regulation on discards, which culminated in January 2019 with the landing obligation of all regulated commercial species in European waters (Stokstad, 2019). Therefore, although food loss will diminish in marine fisheries, there are fears that food loss from landed unwanted fish may just be pushed back to the postharvesting stage. Nevertheless, preliminary studies indicate that the valorization of landed unwanted fish could be implemented through a variety of pathways, including bioproducts (Yan and Chen 2015; Suresh et al. 2018; Vázquez et al. 2019), animal feed, food applications, industrial uses or fertilizers (Iñarra et al. 2019).

Regarding agricultural products, such as fruits, similar strategies can be established for food loss generated in the agricultural stage, including waste-to-energy valorization approaches (Cuéllar and Webber 2010; Vilariño et al. 2017) or the extraction of different types of pharmacological, chemical or cosmetic compounds (Lin et al. 2013). Interestingly, the other life cycle stage that generates high amounts of FLW is the consumption stage, which implies a more diffuse generation of the residues in households or restaurants. In the case of pomegranate, for instance, the two main formats in which this fruit is presented to the consumers is either whole fresh or in arils in some type of plastic packaging. The former implies that the peel waste (over $50 \%$ of the total weight) is discarded in the households with a mix of different organic wastes (Vázquez-Rowe et al. 2017b). The latter implies that the peel waste is generated in high quantities in processing plants prior to packing the arils and, therefore. Considering that pomegranate peel has important pharmacological properties (Akhtar et al. 2015; Khoddami and Roberts, 2015), the value added of concentrating the waste in the processing stage is significant, as long as the location allows the delivery to the pharmaceutical industry. Otherwise, the treatment possibilities 
of the residue will probably converge with the organic mix in the household, which will undergo the specific waste treatment techniques established in a particular town or city for municipal solid waste (Vázquez-Rowe et al. 2017b). On the other hand, Figure 8b displays a graphical representation of the life cycle stage where the NFC is occurring when equal weighting factors are used. These results indicate that, for example, LP optimization lead to a higher relative importance of red meat and vegetable fats due to their optimized weighting factor values are higher than values using equal weighting factors. This is because their economical cost is higher and consequently, the economical losses are greater.

Based on this discussion, specific food waste management strategies should be established, not only for the different food categories or products identified, but also considering the different stages of the supply chain and the geopolitical and climatic considerations of where the residue is being produced.

\section{a) Optimized weigting factors}

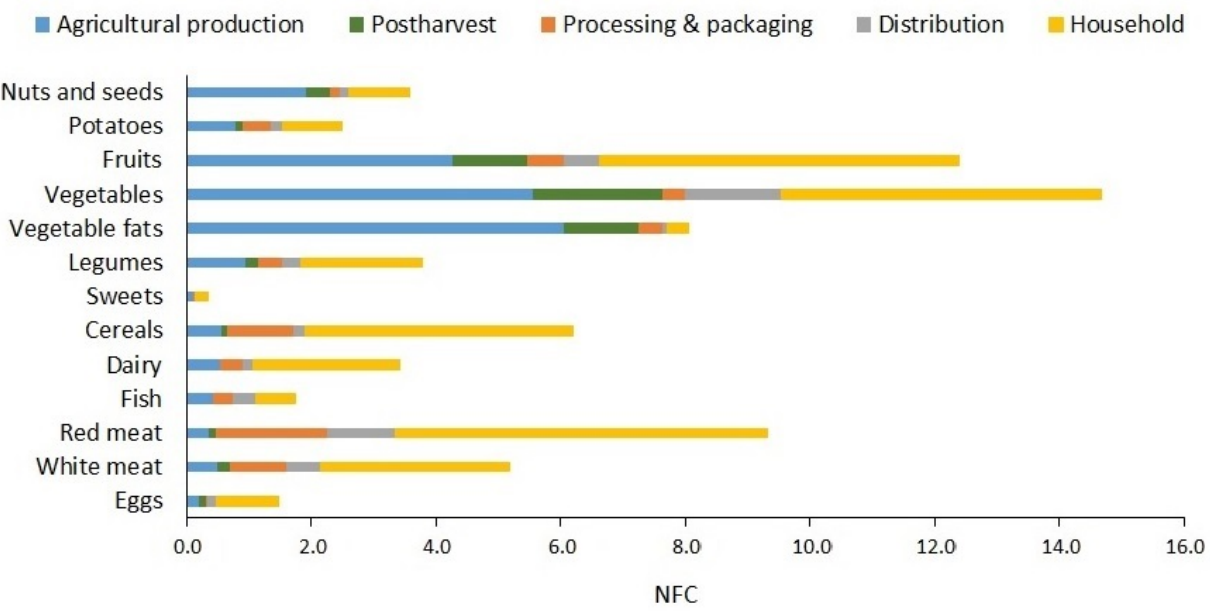

b) Equal weigting factors

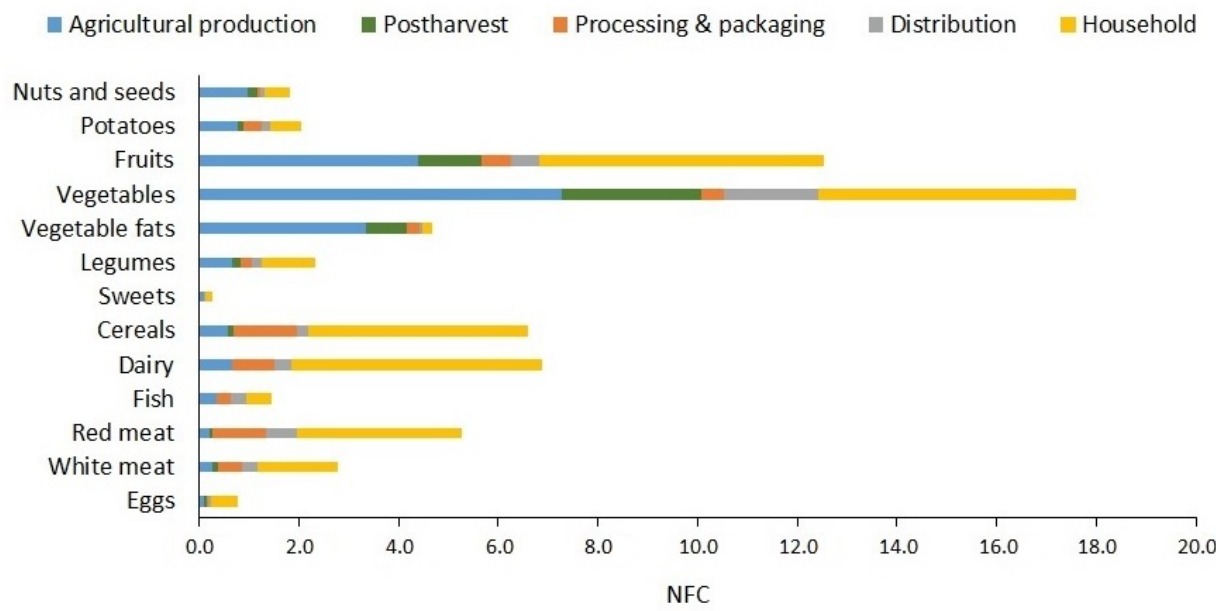


Figure 8. Nutritional Cost Footprint (NCF) for the different categories in each life cycle stage: a) with optimized weighting factors and b) equal weighting factors.

\subsection{Sensitivity analysis}

Once the weighting factors of NRF9.3 and EFLW were estimated and the optimum NCF was calculated, the influence of the relative importance assigned to each index is analyzed. Hence, $\alpha_{i}$ and $\beta_{i}$ is carried within the 1-0 range. As shown Figure 9, results were mostly independent from the importance attributed to either nutritional $\left(\mathrm{Ni}^{*}\right)$ or economic $\left(\mathrm{Ci}^{*}\right)$ variables, since vegetables and fruits presented the greatest NCF values regardless of the variation of $\alpha_{i}$ and $\beta_{i}$, except when $\beta_{i}$ is estimated at 1 , that is to say, when NCF is only based on the economical variable, in which red meat had a higher NCF than fruits. On the other hand, sweets and eggs seemed to be the most nutritional-economic efficient food categories, except when $\alpha_{i}$ is estimated at 1 . In this case, when NCF is composed only by the nutritional variable, nuts and seeds was the food category with the lowest NCF. For the range $0.25 \leq \alpha_{i}, \beta_{i} \leq 0.75$ the results did not follow any trend. In addition, the cells that represent the closest values of the optimized $\alpha_{i}$ and $\beta_{i}$ are highlighted with a black box. The weighting method allows shifting the NCF index towards those foods with higher cost and, in addition, foods with lower NRF9.3.

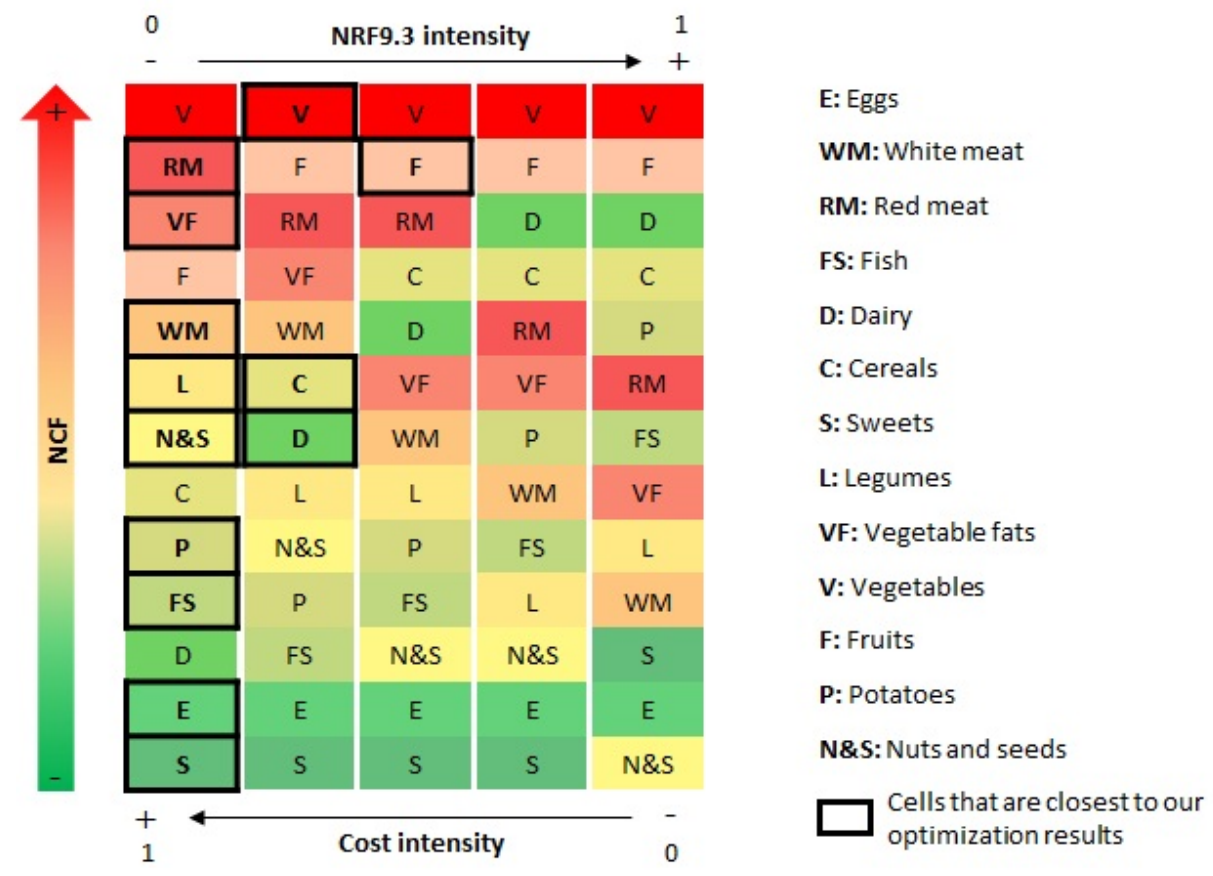

Figure 9. Sensitivity analysis for the Nutritional Cost Footprint (NCF) for the different categories throughout the entire supply chain of agri-food systems in Spain. 


\section{Conclusions}

Current FLW policies tend to obviate the fact that different stages of the supply chain may present different behavior in terms of FLW efficiency. In fact, most policies currently set reduction targets only at consumer level, limiting the efficacy of these policies. In contrast, climate action proposals by nations to reduce their GHG emissions tend to focus on agriculture and farming, but do not tend to include consumer-based targets. Therefore, in many cases FLW, waste recovery pathways and climate change reduction targets are not harmonized throughout the supply chain. In this context, the results presented in the current study highlight the need to establish specific strategies depending on critical food categories and supply stages. More specifically, categories such as vegetables, cereals or fruit, where found to be not only the categories with a greater bulk amount of FLW generated, but also in terms of economic value loss and nutritional loss. This reveals the need of expanding the FLW scope beyond mass quantity, including the nutritional and economic variables as a measure of FLW. Moreover, these results will allow policy-makers and other stakeholders linked to the food sector, but also to waste management and nutrition, to generate category-specific strategies to minimize FLW, including awareness campaigns, technological advancements, changes in waste management criteria or strategies to feed the hungry or animals in which nutritional and cost variables have critical influence. It should be noted that although the results are presented for a case study in Spain, the methodology is applicable to any local, regional or national context that is desired. In fact, a relevant future outcome would be to establish prospective studies in which the variation in climatic or economic variables may influence the results presented.

The limited utility of the waste hierarchy approach, together with an over inclusive definition of waste, both of which fail to mediate tensions between waste management (what we do with stuff once it becomes waste) and waste prevention (preventing stuff from becoming waste in the first place), is clearly visible with the results presented. For instance, waste reduction strategies may conflict with the increasing interest in using food waste fractions for bioenergy generation. In fact, those strategies aimed at simply halving the amount of waste generated may hinder energy policies seeking to expand bioenergy production as means for GHG emissions mitigation. Therefore, the nutritional and economic dimensions analyzed in this study value the need to consider waste food management as the best way to prevent and divert resources beyond the benefits for the environment, including an additional, and implicit, social and economic framework in the decision-making process.

\section{Acknowledgements}


The authors are grateful for the funding of the Spanish Ministry of Economy and Competitiveness through the

Ceres-Procom: Food production and consumption strategies for climate change mitigation (CTM2016-76176-C21-R) (AEI/FEDER, UE).

\section{References}

Akhtar S, Ismail T, Fraternale D, Sestili P (2015). Pomegranate peel and peel extracts: Chemistry and food features. Food Chem 174:417-425.

Batlle-Bayer L, Bala A, García-Herrero I, Lemaire E, Song G, Aldaco R, Fullana-i-Palmer P (2019) The Spanish Dietary Guidelines: A potential tool to reduce greenhouse gas emissions of current dietary patterns. J Clean Prod 213:588-598.

Bradshaw C (2018) Waste Law and the Value of Food. J Environ Law 30(2):311-331.

Cristobal J, Castellani V, Manfredi S, Sala S (2008). Prioritizing and optimizing sustainable measures for food waste prevention and management. Waste Manage 72:3-16.

Cuéllar AD, Webber ME (2010). Wasted food, wasted energy: the embedded energy in food waste in the United States. Environ Sci Technol 44(16):6464-6469.

Datacomex (2018). Estadísticas del comercio exterior español. Agencia Española de Administración Tributaria. Retrieved from: http://datacomex.comercio.es/. Latest access: February $4^{\text {th }} 2019$ [in Spanish].

de Souza R, Schincaglia R, Pimentel G, Mota J (2017). Nuts and human health outcomes: A systematic review. Nutrients 9(12):1311.

Drewnowski A, Maillot M, Darmon N (2008) Should nutrient profiles be based on 100 kcal, 100g or serving size? Eur J Clin Nutr 63 (7):898-904.

Drewnowski A, Maillot M, Darmon N (2009) Testing nutrient profile models in relation to energy density and energy cost. Eur J Clin Nutr 63 (5):674-83.

Drewnowski A (2010) The Nutrient Rich Foods Index helps to identify healthy, affordable foods. Am J Clin Nutr 91: 1095S-1101S.

EFSA (2017) Dietary Reference Values for Nutrients Summary Report. Retrieved from: https://doi.org/10.2903/sp.efsa.2017.e15121. Latest access: February $4^{\text {th }} 2019$.

Eriksson M, Strid I, Hansson PA (2015) Carbon footprint of food waste management options in the waste hierarchy—a Swedish case study. J Cleaner Prod 93:115-125.

Eurostat (2015a) Fishery production in all fishing regions. Retrieved from: https://ec.europa.eu/eurostat/web/fisheries/data. Latest access: February $4^{\text {th }} 2019$. 
Eurostat (2015b) Production and utilization of milk on the farm - annual data. Retrieved from: https://ec.europa.eu/eurostat/web/agriculture/data/database. Latest access: February $4^{\text {th }} 2019$.

Eurostat. (2015c) Slaughtering in slaughterhouses - annual data. Retrieved from: https://ec.europa.eu/eurostat/web/agriculture/data/database. Latest access: February $4^{\text {th }} 2019$.

Eurostat, (2015d) Crop products - $\quad$ annual data. Retrieved from: https://ec.europa.eu/eurostat/web/agriculture/data/database. Latest access: February $4^{\text {th }} 2019$.

FAO (2015) Food Balance Sheets, Spain 2013. Food and Agriculture Organization of the United Nations. Retrieved from: http://www.fao.org/faostat/en/\#data/FBS. Latest access: February $4^{\text {th }} 2019$.

Farran A, Zamora R, Cervera P (2004) Tablas de composición de alimentos del CESNID. Retrieved from: http://www.sennutricion.org/es/2013/05/13/tablas-de-composicin-de-alimentos-del-cesnid. Latest acces: February $5^{\text {th }} 2019$ [in Spanish].

Fulgoni VL, Keast DR, Drewnowski A (2009) Development and Validation of the Nutrient-Rich Foods Index: A Tool to Measure Nutritional Quality of Foods. J Nutr 139 (8):1549-1554.

García-Herrero I, Laso J, Margallo M, Bala A, Gazulla C, Fullana P, Vázquez-Rowe I, Irabien A, Aldaco R (2017) Incorporating linear programing and life cycle thinking into environmental sustainability decision-making: a case study on anchovy canning industry. Clean Tech Environ Policy 19(7): 1897-1912.

García-Herrero I, Hoehn D, Margallo M, Laso J, Bala A, Batlle-Bayer L, Fullana P, Vázquez-Rowe I, Gonzalez MJ, Durá MJ, Sarabia C, Abajas C, Amo-Setien FJ, Quiñones A, Aldaco R (2018) On the estimation of potential food waste reduction to support sustainable production and consumption policies. Food Policy 80:24-38.

Grizzetti B, Pretato U, Lassaletta L, Billen G, Garnier J (2013) The contribution of food waste to global and European nitrogen pollution. Environ Sci Pol 33:186-195

Guenther PM, Reedy J, Krebs-Smith SM (2008). Development of the healthy eating index-2005. J Am Diet Assoc 108(11):1896-1901.

Gustavsson J, Cederberg C, Sonesson U, Van Otterdijk R, Meybeck A (2011) Global Food Losses and Food Waste; Extent, Causes and Prevention. Swedish Institute for Food and Biotechnology (SIK), Gothenburg (Sweden), and FAO. Rome, Italy.

Heller MC, Keoleian GA (2015) Greenhouse gas emission estimates of US dietary choices and food loss. J Ind Ecol 19(3):391-401.

Hellweg S, Milà i Canals L (2014) Emerging approaches, challenges and opportunities in life cycle assessment. Science, 344(6188):1109-1113. 
Iñarra B, Bald C, Cebrián M, Antelo LT, Franco-Uría A, Vázquez JA, et al. (2019). What to do with unwanted catches: Valorisation options and selection strategies. In: The European Landing Obligation, pp. 333-359. Springer, Cham.

ISO (2006a) ISO 14040: Environmental management-life cycle assessment - principles and framework. International Standards Organization, Geneva.

ISO (2006b) ISO 14044: Environmental management-life cycle assessment - requirements and management.. International Standards Organization, Geneva.

Kennedy ET, Ohls J, Carlson S, Fleming K (1995) The healthy eating index: design and applications. J Am Diet Assoc 95(10):1103-1108.

Khoddami A, Roberts TH (2015). Pomegranate oil as a valuable pharmaceutical and nutraceutical. Lipid Technol 27(2):40-42.

Laso J, Hoehn D, Margallo M, García-Herrero I, Batlle-Bayer L, Bala, A, Fullana P, Vázquez-Rowe I, Irabien A, Aldaco R (2018a) Assessing energy and environmental efficiency of the Spanish agri-food system using the LCA/DEA methodology. Energies, 11(12), 3395.

Laso J, García-Herrero I, Margallo M, Vázquez-Rowe I, Fullana P, Bala A, Gazulla C, Irabien A, Aldaco R (2018b) Finding an economic and environmental balance in value chains based on circular economy thinking: An eco-efficiency methodology applied to the fish canning industry. Resour Conserv Recy 133:428-437.

Lin CSK, Pfaltzgraff LA, Herrero-Davila L, Mubofu EB, Abderrahim S, Clark JH, et al. (2013). Food waste as a valuable resource for the production of chemicals, materials and fuels. Current situation and global perspective. Energ Environ Sci 6(2):426-464.

Lorenzo-Toja Y, Vázquez-Rowe I, Chenel S, Marín-Navarro D, Moreira MT, Feijoo G (2015) Eco-efficiency analysis of Spanish WWTPs using the LCA+DEA method. Water Res 68:651-666.

Lovejoy JC (2005). The impact of nuts on diabetes and diabetes risk. Curr Diabetes Rep 5(5):379-384.

MAPAMA, 2013. Las pérdidas y el desperdicio alimentario generado por la producción agrícola de alimentos en España. Spanish Ministry of Agriculture, Fishery, Food and Enviroment. Retrieved from: https://www.mapa.gob.es/es/alimentacion/temas/estrategia-mas-alimento-menos-

desperdicio/Memoria\%20de\%20actividades_2013_tcm30-78798.pdf. Latest access: February $4^{\text {th }} 2019$ [in Spanish]. 
MAPAMA, 2015. Ministry of Agriculture, Fishery, Food and Environment. Agricultural statistics-National average prices. Retrieved from: https://www.mapa.gob.es/app/precios-medios-nacionales/pmn_tabla.asp. Last Access: May 6th 2019 [in Spanish].

MAPAMA, 2017, Spanish Ministry of Agriculture, Fishery, Food and Environment. Household Consumption. Database. Retrieved from: www.mapama.gob.es/es/alimentacion/temas/consumo-ycomercializacion-y- distribucion-alimentaria/panel-de-consumo-alimentario/base-de-datos-de-consumo-enhogares/. Last accessed: February 5 $5^{\text {th }} 2019$ [in Spanish].

MINECO, 2015. Ministry of Economy and Competitiveness. Prices at source and destination. Retrieved from: http://www.comercio.gob.es/es-ES/comercio-interior/Precios-Comerciales/Informacion-de-precios-(bases-dedatos)/Paginas/Precios-Origen-Destino-.aspx. Last access: May 6 $6^{\text {th }} 2019$ [in Spanish].

Nemecek T, Jungbluth N, i Canals LM, Schenck R (2016) Environmental impacts of food consumption and nutrition: where are we and what is next? Int J Life Cycle Assess 21(5):607-620.

Pimentel D, Pimentel M.H. (Eds.) (2008) Food, energy, and society. CRC press.

Ravindran R, Jaiswal AK (2016) Exploitation of food industry waste for high-value products. Trends Biotechnol 34(1):58-69.

Stokstad E (2019). Ships banned from throwing unwanted fish overboard. Science 363(6423), 112-113.

Suresh PV, Kudre TG, Johny LC (2018) Sustainable Valorization of Seafood Processing By-Product/Discard. In: Singhania R., Agarwal R., Kumar R., Sukumaran R. (eds) Waste to Wealth. Energy, Environment, and Sustainability. Springer, Singapore

Sluik D, Streppel MT, van Lee L, Geelen A, Feskens E (2015) Evaluantion of a nutrient-rich food index score in the Netherlands. J Nutr Sci 4(14): 1-9.

UN (2019) Sustainable Development Goal 12 - Ensure Sustainable consumption and production patterns. United Nations. Retrieved from: https://sustainabledevelopment.un.org/sdg12. Latest access: February $4^{\text {th }} 2019$.

Vázquez JA, Fernández-Compás A, Blanco M, Rodríguez-Amado I, Moreno H, Borderías J, Pérez-Martín RI (2019). Development of bioprocesses for the integral valorisation of fish discards. Biochem Eng J 144:198-208. Vázquez-Rowe I, Larrea-Gallegos G, Villanueva-Rey P, Gilardino A (2017a) Climate change mitigation opportunities based on carbon footprint estimates of dietary patterns in Peru. PloSone, 12(11):e0188182.

Vázquez-Rowe I, Kahhat R, Santillán-Saldívar J, Quispe I, Bentín M (2017b). Carbon footprint of pomegranate (Punica granatum) cultivation in a hyper-arid region in coastal Peru. Int J Life Cycle Assess 22(4):601-617. 
Vazquez-Rowe I, Moreira MT, Feijoo G (2011). Estimating global discards and their potential reduction for the Galician fishing fleet (NW Spain). Mar Policy 35(2):140-147.

Vilariño MV, Franco C, Quarrington C (2017). Food loss and waste reduction as an integral part of a circular economy. Frontiers Environ Sci 5:21.

WHO (2015) Healthy Diet. Fact Sheet Nº394. September 2015. World Health Organization. Retrieved from: https://www.who.int/en/news-room/fact-sheets/detail/healthy-diet. Latest access: February 5 2019.

Yan N, Chen X (2015). Sustainability: Don't waste seafood waste. Nature News 524(7564):155.

Yang Y (2016) Toward a more accurate regionalized life cycle inventory. J Clean Prod 112:308-315. 